\title{
POSTPRINT
}

\section{Frames change in language contact environments}

\author{
A case study of schleichen ('to sneak') and \\ kommen ('to come')
}

\author{
David Hünlich \\ Institut für Deutsche Sprache
}

\begin{abstract}
Based on the empirical data of 97 fourth-graders from three districts of Braunschweig in Germany, this paper investigates the possibility of changing semantic frames in multilingual communities. The focus of study is the verb field of self-motion. In a free-sorting task involving 52 verbs, Turkish-speaking students, in particular, placed the verbs schleichen ('to sneak') and kommen ('to come') in the same group. When explaining the perceived similarity they also used the word schleichen ('to sneak'), in a specific grammatical construction that is not found in Standard German. This paper suggests that semantic frames may change along with grammatical constructions when typologically distinct languages come into close contact.
\end{abstract}

Keywords: Frame Semantics, language contact, semantic change, free-sorting, migration linguistics

\section{Introduction}

Viewing language contact through the lens of Construction Grammar, as this volume does, inevitably leads to considerations about the effect of contact situations on semantic frames. Like Construction Grammar, Frame Semantics is rooted in Fillmore's (1968) work on case grammar, and espouses a view of language that emphasizes "a continuity between grammar and lexicon," in which "each lexical item carries with it instructions," specifying its place in the "larger semantic-syntactic structure" (Fillmore 2008: 49). While constructions refer to linguistic elements consisting of form-meaning pairs, frames (henceforth simply 'frames') focus on the broader conceptual representations these constructions operate on. Recent research 
on text corpora has shown that although constructions and frames approach language from different directions, they can help explain each other (cf. Fillmore \& Atkins 1992, Fillmore 2008, Croft 2009). This mutual relationship likely also holds for multilingual environments. Exploring this relationship from a frame-semantic perspective, based on test-data from multilingual speakers, is the goal of this paper.

The starting point of the paper is that conflicting semantic frames would be problematic to handle for an integrated bilingual language system such as Höder's (2012) suggestion of a Diasystematic Construction Grammar (DCxG). For the example of Standard German and Low German, Höder (2014) suggests that bilingual constructions undergo change over time at the morphological and lexical surface in order to reach a more homogenous representation across languages. In support of this suggestion, one could also consider the possibility of frames moving closer together and possibly even merging in the future. The data presented in this paper can be interpreted as an indication that such change is underway in German, specifically where lexical units evoking the Self_Motion and Arriving frames are in contact with Turkish.

Data for this paper come from sorting tests conducted at three schools with a total of 97 fourth graders in three socioeconomically distinct districts of Braunschweig, a medium-sized city in Germany with around 250.000 inhabitants. By freely ordering the lexical field of German self-motion verbs the participants revealed differences in the way monolinguals and multilinguals perceive the meaning of certain 'descriptive verbs' (Snell-Hornby 1983), such as the verb schleichen ('to sneak'). German contains an abundance of such verbs, which encode the manner of motion directly in the verb stem instead of qualifying manner by means of a modifying attribute (e.g. 'silently, secretly'). Turkish has many fewer verbs of this type, so there is reason to believe language contact could play a role in the way certain frames change. At the same time, there are grammatical constructions that occur in newly emerging vernaculars of German that may also trigger the phenomenon of changing frames.

This paper is structured as follows. The next section provides some background on Frame Semantics and on the expression of motion events across languages. The third section describes the methodology employed in the study and introduces the speaker groups and the relevant background data. The results of the free-sorting task are presented in the fourth section in the form of dendrograms and with help of a regression analysis. A video-guided feedback session in Section 5 served to examine some peculiar properties of the verb schleichen ('to sneak') in its relationship to the verb kommen ('to come'). Section 6 discusses a possible novel frame in light of the properties of the Self_Motion and Arriving frame. The final section summarizes the findings and underscores the importance for future research on language contact not only in terms of constructions, but also in terms of frames. 


\section{Background}

\subsection{Frame Semantics and FrameNet}

Fillmore (1982: 111) describes the frame-semantic approach as being "most akin to ethnographic semantics, the work of the anthropologist who moves into an alien culture and asks such questions as 'What categories of experience are encoded by the members of this speech community through the linguistic choices that they make when they talk?" Accordingly, pinpointing categories of experience, so-called frames, is the key to understanding the meaning of words. Frames are the "conceptual prerequisite for understanding the meaning" of words and speakers know the "meaning of the word only by first understanding" the frame it is embedded in (Fillmore \& Atkins 1992: 76-77).

A practical project resulting from this theory is the frame-based, lexicographic database FrameNet, an annotated, searchable online corpus that serves to exemplify and explore frames and lexical units within the British National Corpus (BNC) (Baker et al. 1998). Lexical units (LUs) are words thought to evoke certain frames. Over 13,000 such lexical units evoking over 1,200 frames have been annotated thus far. ${ }^{1}$ A central part of FrameNet is a representation of its frame elements (FEs), or the semantic roles that constitute the particular frame. Consider the definition of the Self_Motion frame which is evoked by LUs such as amble, climb, crawl, hike, hop, run, saunter, sneak, stumble and walk: ${ }^{2}$

The Self-mover, a living being, moves under its own direction along a Path.

She WALKED along the road for a while.

Gloss: Self-mover (Core) Lexical Unit Path (Core) Duration (Non-Core)

Many of the lexical units in this frame can also describe the motion of vehicles (e.g., as external arguments). We treat these as belonging in this frame.

The cars SCOOTED slowly towards the intersection.

Gloss: Self-mover (Core) Lexical Unit Speed (Non-Core) Direction (Core)

Self_motion most prototypically involves individuals moving under their own power by means of their bodies. Many words also specify the manner of motion (swim, walk). This frame contains mostly words that fit this prototypical scenario, but the frame itself does not specify whether a separate vehicle is impossible, necessary, or unspecified. Lexical units that involve separate vehicles are associated with FEs that are not appropriate for the more general case of motion, so they are

1. http://www.paulallen.ca/documents/2015/10/framenet-1-6-general-release-notes-2015.pdf

2. Instead of the typical color-coding in FrameNet, I am using a gloss here to point out which of the FEs are core and non-core elements. 
placed in the Operate_vehicle or Ride_vehicle frames (e.g., He drove across the country, She flew to Europe) ${ }^{3}$

The definition and examples make clear that the Self_Motion frame refers to a self-moving person or object as one of its core components. Motion events that would violate this principle are excluded (e.g. driving, etc.). The examples contain a number of FEs that can occur with the Self_Motion frame. (All FEs of the frame are listed online below the initial definition.) FEs fall into the categories 'Core' and 'Non-core.' Core FEs are central to the specific frame defined, while non-core FEs are also shared by other frames and are not mandatory for the frame to function (e.g. TIME, MANNER, etc.).

In addition to this fundamental information on the frame, Lexical Entry Reports index the over 9,000 LUs defined in FrameNet. Each of these reports has three parts: the first is a short definition of the LU, such as the definition of the verb sneak: to "move, go, or convey in a furtive or stealthy manner." ${ }^{4}$ Next, the report lists the exact number of every type of FE that occurs with the LU in the annotated corpus instances. For example, the role of the 'self-mover' is evoked by sneak in 72 sentences (so, actually, in every sentence containing the verb). Given the definition of the Self_Motion frame that contains a SELF-MOVER as a core-FE, this distribution is expected. The non-core-FE MANNER, by contrast, occurs in only seven frames evoked by sneak. Since MANNER is counted as a peripheral FE, a low count of realizations is not surprising. ${ }^{5}$

The final and perhaps most important part of the Lexical Entry Report is a presentation of valence patterns that occur across the examples. This view reveals how and in what order each FE of the frame is realized syntactically with the LU in question. For the LU sneak, it stands out, for instance, that the SELF-MOVER is an $\mathrm{NP}$ in 70 cases. In two cases, however, the SELF-MOVER is not instantiated due to an infinitive construction, as in Example (1) below. While the 'Sneaker' is implied, there is no lexical representation.

\section{(1) I imagine it would be virtually impossible to SNEAK up on an owl.}

In sum, FrameNet is a powerful illustration of how frame semantics can be applied to natural language corpora. However, the BNC is a monolingual resource

3. https://framenet2.icsi.berkeley.edu/fnReports/data/frameIndex.xml?frame=Self_motion

4. https://framenet2.icsi.berkeley.edu/fnReports/data/lu/lu1227.xml?mode=lexentry\&banner=

5. Note, however, that the presence or absence of a 'MANNER' element does not tell us whether manner is a semantic property of the sentence. The Lexical Entry Report simply tells us whether 'MANNER' is realized by its own lexical element in sentences with sneak. See the discussion in $\mathbf{2 . 2}$ for more detail on this question. 
and there are many open questions on frame-relations in a multilingual setting that FrameNet cannot answer. The next section highlights some of these challenges for Frame Semantics. For this purpose we will imagine a hypothetical corpus of mixed language data involving the two typologically distinct languages Turkish and German.

\subsection{Moving across languages}

A considerable minority of Turkish guest workers and their families immigrated to Germany in the 1960s through the 1980 s, such that today bilingual TurkishGerman speakers make up between $20 \%$ and $80 \%$ of the population in certain neighborhoods of many large and medium-sized German cities. In our imaginary project, we would record everyday language data with the help of portable clip-microphones from many bilingual individuals in these communities over the course of one year. ${ }^{6}$ In the process of reviewing the data, we would find many sentences evoking the Self_Motion frame in both Turkish and German due to the ubiquitous nature of the frame. While annotating these instances using FrameNet methods, we would notice some important structural differences between Turkish and German. The German self-motion events would often involve Lexical Units that encode MANNER in the verb stem. The verb schleichen 'to sneak,' for instance, does not only account for a motion event, but highlights the manner with which the motion is performed. Examples (2) and (3) below illustrate this. Sencence (3) can be seen as a semantic decomposition of (2).

(2) Der Mann schleicht the.m man sneaks.

'The man is sneaking'.

(3) Der Mann bewegt sich leise, vorsichtig und langsam. the.m man move himself quietly carefully and slowly.

'The man is moving quietly, carefully and slowly.'

In contrast, we would find that Turkish encodes the directional information of the motion event in the verb itself with an additional case marker on the noun, while MANNER is always optionally expressed through an adverb, as in (4), below. Here, the word gizlice ('secretly') expresses the manner of motion.

6. Currently there is no such corpus available to the knowledge of the author. There are several bilingual corpora, but they are not community-based, bridging age groups and they usually only involve few individuals. A breadth of bilingual data even vaguely comparable to the $\mathrm{BNC}$ is not available at this point. 
(4) Ogizlice ev-e gir-di

3 secretly house-DAT go.in-PST

'S/he snuck into the house.'

Literally: 'S/he secretly entered the house.'

At this point, our annotation team would have to confront a rather difficult question: if MANNER is encoded as an optional frame element in Turkish but as part of the Lexical Unit in German can we assume that the Self_Motion frame is the same in its conceptual nature and scope across the two languages? It seems unlikely.

Research in linguistic typology also suggests a negative answer. Snell-Hornby's (1983) study of 'verb descriptivity', for instance, shows that languages such as German and English possess many verbs that Turkish does not have. In German numerous verbs consist of an 'act-nucleus' and a modifying complex of elements. The modifying elements leise ('quiet'), vorsichtig ('careful') and langsam ('slow') in (3), for instance, are all implied by the verb schleichen ('to sneak'). These semantic elements are not mandatory for the expression of the motion event in (2), but they are an essential part of its meaning because they are part of the 'descriptive verb' schleichen. So far, FrameNet does not have a means by which these meaningful components of a Lexical Unit like schleichen ('to sneak') could be teased apart. Through the verb, the manner of motion becomes a core element of the frame - perhaps rightly so, because the use of descriptive verbs also has constructional implications.

Languages with many descriptive verbs, like German and English, typically encode the direction of a motion outside the verb stem. A prepositional phrase or additional particle usually fulfil this function, as the aus dem Haus ('out of the house') and hinaus ('out') in (5) below.

(5) Sie schlich aus dem Haus hinaus.

3f sneak.PST out DET.dat house out

'She snuck out of the house.'

Due to the distinctive property of encoding the direction of a motion with help of a satellite vs. a verb, Talmy $(1985,2000)$ distinguishes 'S-languages' (such as German) and 'V-languages' (such as Turkish) in a typological framework. The Lexical Units of V-languages often encode the direction of motion but do not include information on MANNER and vice versa. Table (1) summarizes the differing distributions seen in (4) and (5).

Several studies show that the properties of S- and V-languages exert distinct influences on the communicative thought process (cf. Slobin 1996, Özçalişkan \& Slobin 1999, Slobin 2000). For a bilingual FrameNet, this raises important questions: How do speakers unify two different ways of thinking about the same event? How should one deal with conflicting definitions of the same frame? At first 
Table 1. Syntactic-Semantic Alignment in Turkish and German Motion Events

German (S-language):

Grammatical Function: Subject finite verb

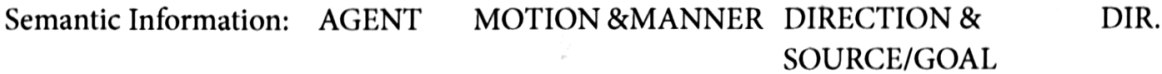

Sie aus dem Haus hinaus.

3sf sneak.PST out DET.dat house out

'She snuck out of the house.

Turkish (V-language):

Grammatical Function: adverb indirect object finite verb

Semantic Information: MANNER GOAL \& DIRECTION MOTION \& DIRECTION \& AGENT

gizlice ev-e gir-di.

secretly house-DAT go.in-PST

'She snuck into the house.'

Literally: 'She secretly entered the house'

DIRECTION

German (S-language): particle prepositional phrase hinaus aus dem Haus

Turkish (V-language): verb indirect object

girdi ev-e
MANNER MOTION

verb verb

schlich schlich

adverb verb

gizlice $\quad$ girdi

glance, a solution arises from the literal translation of the Turkish example: the verb girmek is similar in meaning to the English verb 'to enter'. FrameNet suggests to treat verbs such as 'to come' and 'to enter' in a frame separate from the concept of Self_Motion. English verbs that have an inherently directional component are thought to evoke frames for which directionality plays a central role, such as Arriving or Departing. The same would hold for the German verb kommen ('to come'). Together with Self_Motion, the Arriving frame inherits properties from the greater Motion frame. Turkish motion verbs could also be viewed as evoking the Arriving (or Departing) frame thus eschewing the problem of a conflicting definition of Self_Motion. However, such a solution raises an intriguing question: is it perceivable and sensible that a bilingual speaker's same "category of experience" (Fillmore 1982: 111) is associated with two separate and yet closely related frames? This is a dilemma not only for a hypothetical application of Frame Semantics on a bilingual corpus, but also for the current structure of FrameNet: if the proposed frames (resulting from corpus analysis and a multistage decision process among 
experts) cannot represent the same experience across languages - could they be inherently flawed?

An answer to this apparent quandary may lie in recent research on GermanTurkish bilinguals. Goschler et al. (2013), for instance, also indicate Turkish influences on the German of bilingual speakers: focusing on differences in the structuring of motion events between monolingual German and bilingual Turkish-German speakers in the Kiezdeutsch corpus ${ }^{7}$ they find that Turkish-German bilinguals use the generic German verbs gehen ('to go') and kommen ('to come') more often than Snell Hornby's (1983) 'descriptive verbs.' They argue that this is due to an avoidance strategy: Turkish-German bilinguals appear to avoid 'descriptive verbs' when employing directional (РATH) satellites. In a frequency analysis including the variables 'language (German/Turkish-German)', 'verb type (Manner/Generic)', and ' presence or absence of a directional satellite, they find that German monolinguals use manner verbs with satellites at rates significantly higher than the expected frequency, while Turkish-German bilinguals use such patterns significantly less frequently. This leads the authors to conclude "that the effects reported are due exclusively to the fact that bilingual Turkish-German speakers avoid the combination of MANNER verbs with PATH satellites, while monolingual German speakers actually prefer this combination" (Goschler et al. 2013: 246). This discrepancy attested by Goschler et al. opens up a new possibility: assuming there is only one frame at work when speakers encode the concepts attributed to a motion event, could it be that the bilinguals are homogenizing the Self_Motion frame from German with the Arriving frame from Turkish leading to a unique frame that only operates for bilinguals? The experiment I conducted with children in Braunschweig points in this direction. The next section describes the method I employed.

\section{Methodology}

\subsection{The Free Sorting Method}

In her treatment of the 'core' meaning and modifying elements of 'descriptive verbs', Snell-Hornby (1983) constructed field diagrams plotted over two dimensions to approximate the similarities and differences of verbs in German and English. Figure (1) below is taken from a subfield of self-motion verbs, which she labels 'nimble, with energy': the word hüpfen ('to hop') is closely aligned with springen ('to jump'). The arrow is a simple way of indicating a semantic relationship.

7. The Kiezdeutsch corpus is a mainly monolingual corpus of German representing youth language data from multicultural neighborhoods of Berlin. It is accessible on demand. 
There appears to be no immediate relationship between the 'jumping' verbs to the right and to the left, which include klettern ('to climb') and krabbeln ('to crawl (on hands and feet)').

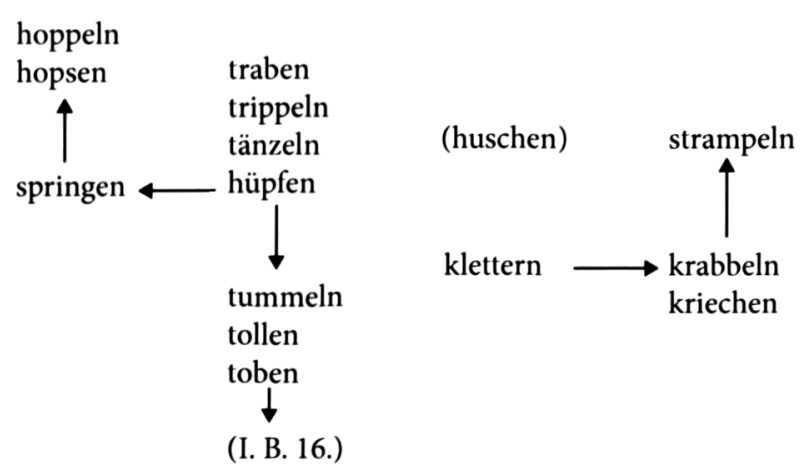

Figure 1. Subfield 'Nimble, with energy' (Snell-Hornby 1983: 140)

Snell-Hornby justifies the relationships she posits with help of Standard German dictionary entries, a small corpus of texts and judgments from three native speakers. While her project clearly differs from FrameNet, it can be interpreted from a frame-semantic perspective: Snell-Hornby is investigating the relationships between Lexical Units (LU) that are associated with a certain frame, namely Self Motion. The problem of arriving at semantic relations is the same as in FrameNet: it is ultimately the researcher's intuition (supported by a process of consultation) that suggests what the lexical field looks like.

In order to develop a method to empirically test the way multiple speakers would actually organize the word field, I was inspired by Snell-Hornby's (1983) metaphor of word fields as comparable with the color continuum (Snell-Hornby 1983: 68). ${ }^{8}$ Could fields of lexical meaning be tested in a fashion parallel to the way relativity researchers have been testing color perception across languages? In seeking to better understand possible focal points and borders in color perception and color terminology, Roberson et al. (2005) conducted a free-sorting task of color squares with speakers of 17 distinct languages. Participants freely grouped color terms "so that ones that looked similar were placed together in the way that members of a family go together" (8). The free-sorting method was used because it allowed for an unrestrained grouping of colors as well as a comparison of naming practices and potential relationships between colors across speaker groups. Roberson et al. (2005) found strong variability between individual speakers, but also a genuine influence of sorting behavior based on learned color categories.

8. For a more detailed description of the free-sorting methodology and its application to semantic fields, see Huenlich (2015). 
At the same time, the existence of focal colors was confirmed due to universal characteristics of sorting behavior across participants and languages. In other words, there is an interaction of individual, sociolinguistically acquired and universal influences on sorting behavior.

While Roberson et al. (2005) used free-sorting to assess the non-verbal perception of their participants, the method can be adapted to test the perception of lexical categories in a language. It requires the use of written phrases printed on cards, but is nevertheless viable. Potential issues with transferring this method include that written texts are processed in fundamentally different ways than spoken language, or that categorization tasks might not be representative of lexical categorization. Conducting the test with students in a school setting circumvents some of these obvious problems to a certain degree: students are familiar with categorization tasks that use written words referring to spoken language, and they frequently make distinctions based on categories of meaning. While keeping in mind that the results will be approximations and not exact representations of mental categories, they very likely still align more closely with speakers' cognitively rooted decisions than a process relying heavily on the opinion of a few researchers and text sources. The next subsection introduces the districts in which I conducted a free-sorting test at local schools with 97 students. It also elaborates on the background data of 39 multilingual participants.

\subsection{Participants: Districts and background data}

Braunschweig is a city with a population of 250,000 in the German Federal State of Niedersachsen (Lower Saxony), about two hours west of Berlin. The larger Braunschweig metropolitan area includes Salzgitter and Wolfsburg, and is known for the prominent economic role of the Volkswagen corporation. Many guest workers from Turkey and other countries came to this region in the 1960s and 1970 s, and $16 \%$ of Braunschweig's population has a migration background, meaning that the person in question or his/her parents immigrated to the area from another country. In the 1990s, a large number of Eastern Europeans with German roots came to Braunschweig. As in other German cities of the same size, migrants are concentrated in working class neighborhoods. Often, the need for housing also caused municipalities to develop new neighborhoods from the bottom up. The Weststadt of Braunschweig, for instance, was built for the purpose of accommodating a growing population in the 1960s and 1970s. The make-up of neighborhoods with a migration history is highly diverse, but certain groups, such as the Turkish and Polish minorities, form socially salient and visible communities.

I found participants for my free-sorting test in schools of three districts - two with a prominent migration history located in the Weststadt and Nordstadt - as 
well as in the middle-class neighborhood of Lehndorf, which is located in the Northwest of the city. The map in Figure (2) shows the three districts. Pins in different shades of grey represent the three participant groups in their respective housing area.

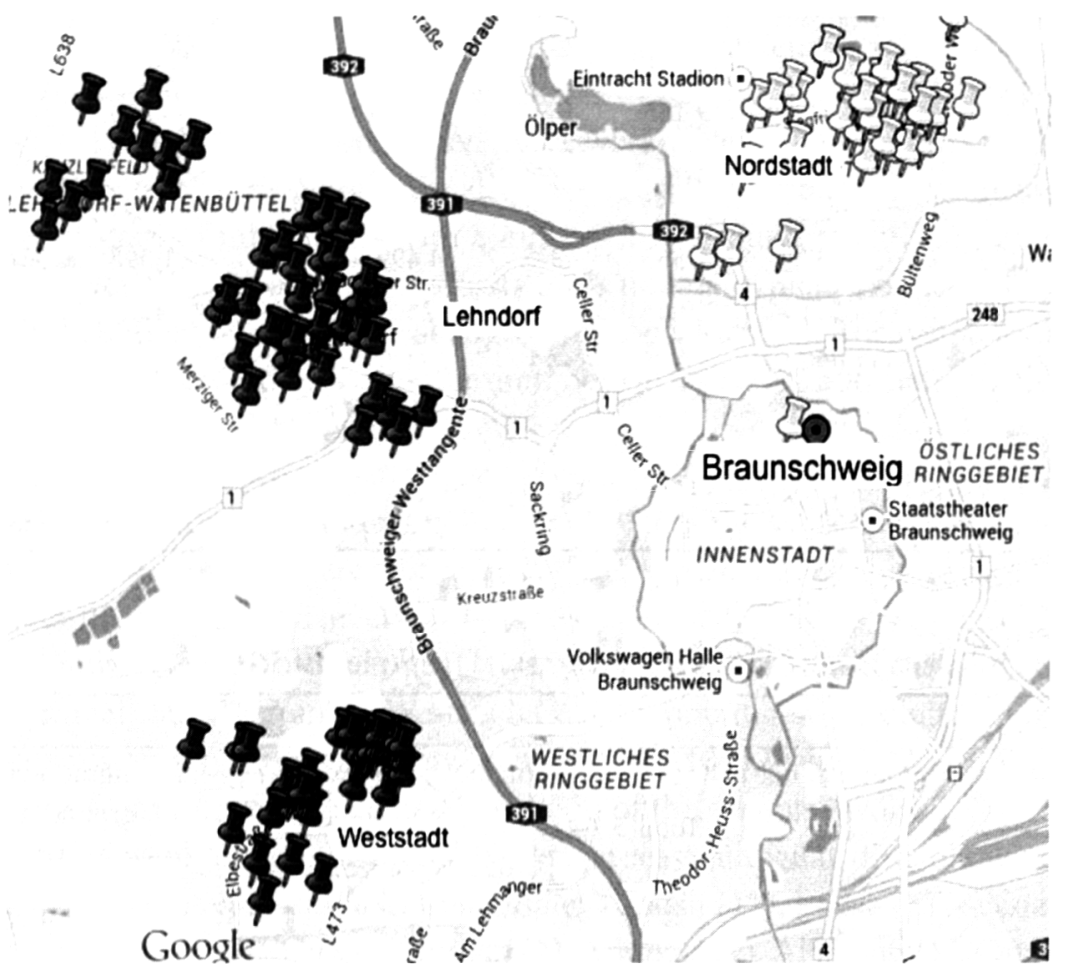

Figure 2. The three districts and the proximity of participants

Tables (2) and (3) illustrate some main differences between the three districts. The Weststadt and Nordstadt are both rather large districts with populations of around 23,000, while Lehndorf has around 11,000 inhabitants. The Weststadt is socioeconomically the lowest of the three neighborhoods with an unemployment rate of $9.6 \%$ and a quarter of the population on welfare. Children are particularly affected by the latter statistic. Having been developed only 50 years ago, the Weststadt is also the youngest of the three districts. In accordance with its original purpose, it still has the largest proportion of inhabitants with a migrant background today $(36.9 \%)$. 
Table 2. Welfare and unemployment rates in three districts of Braunschweig (Data provided by Statistics Institute of Braunschweig)

\begin{tabular}{lccccccc}
\hline & 1 & 2 & 3 & 4 & 5 & 6 & 7 \\
\hline Category: & Population2012 & Unemployed & On welfare & \multicolumn{2}{c}{$\begin{array}{c}\text { Children on } \\
\text { welfare }\end{array}$} \\
Districts: & & Overall & Foreigners & Overall & Foreigners & Overall Foreigners & Fon \\
Braun- & 246742 & 9165 & 1500 & 21.345 & 3.772 & 5.266 & 552 \\
schweig & & & & & & & 17.7 \\
\% & 100 & 5.5 & 9.3 & 11.5 & 17.7 & 17.7 \\
Weststadt & 23537 & 1365 & 328 & 4.499 & 977 & 1.398 & 164 \\
$\%$ & 100 & 9.6 & 16.0 & 25.7 & 21.7 & 42.6 & 11.7 \\
Lehndorf & 11.025 & 268 & 23 & 515 & 71 & 100 & 11 \\
$\%$ & 100 & 4.0 & 6.8 & 6.4 & 13.8 & 7.9 & 11.0 \\
Nordstadt & 23514 & 1124 & 197 & 2.666 & 509 & 654 & 74 \\
$\%$ & 100 & 6.7 & 7.9 & 13.8 & 19.1 & 27.4 & 11.3 \\
\hline
\end{tabular}

* Alt-Lehndorf, Lehndorf Siedlung, Kanzlerfeld and Ölper Holz

Table 3. Inhabitants with "migration background" in three districts of Brauschweig

\begin{tabular}{|c|c|c|c|c|c|c|}
\hline & 1 & 2 & 3 & 4 & 5 & 6 \\
\hline Category: & Population2011 & & rmans & & Foreigners & Migration back- \\
\hline Districts: & & $\operatorname{Total}(3+4)$ & $\begin{array}{c}\text { w/o } \\
\text { dual } \\
\text { citizen- } \\
\text { ship }\end{array}$ & $\begin{array}{l}\text { w/ dual } \\
\text { citizen- } \\
\text { ship }^{* *}\end{array}$ & & ground $(4+5)$ \\
\hline $\begin{array}{l}\text { Braunschweig } \\
\text { total }\end{array}$ & 244806 & 226206 & $\begin{array}{l}203 \\
803\end{array}$ & 22403 & 18600 & 41003 \\
\hline$\%$ & 100 & 92.4 & 83.3 & 9.2 & 7.6 & 16.7 \\
\hline Weststadt & 23268 & 20852 & 14688 & 1642 & 6416 & 8580 \\
\hline$\%$ & 100 & 89.6 & 63.1 & 26.5 & 10.4 & 36.9 \\
\hline Lehndorf & 10978 & 10582 & 10065 & 517 & 396 & 913 \\
\hline$\%$ & 100 & 96.4 & 91.7 & 4.7 & 3.6 & 8.3 \\
\hline Nordstadt & 22027 & 19372 & 17425 & 1947 & 2655 & 4602 \\
\hline$\%$ & 100 & 87.9 & 79.1 & 8.8 & 12,1 & 20.9 \\
\hline
\end{tabular}

** Alt-Lehndorf, Lehndorf Siedlung, Kanzlerfeld and Ölper Holz

Lehndorf represents a strong contrast to the Weststadt: it was a self-governed village before it became a part of Braunschweig in the 1930s, and there are longstanding ties of local families to the district. It is also the district with the lowest 
unemployment (4\%) and welfare rates (6.4\%). The social fabric of the district is mainly middle class, and more recent additions to the area, like Kanzlerfeld, did not change this composition. Lehndorf has the least pronounced migration influence with only $8.3 \%$ of its inhabitants with migration background (which is only half of the average rate in Braunschweig).

Several characteristics make the Nordstadt district demographically and economically distinct from the other two. It was developed in the 1920s for a growing working class population. When guest workers and their families were contracted after WWII the Nordstadt only offered limited space for new inhabitants. The percentage of inhabitants with a migrant background today is $27.4 \%$ which is $16 \%$ lower than in the Weststadt. Its $6.7 \%$ unemployment rate is a bit higher than in Lehndorf but not quite as high as in the Weststadt. The number or welfare recipients are about double the number of Lehndorf and half the number of the Weststadt.

For logistical reasons, I had to restrict data collection in Lehndorf to monolingual speakers, thereby excluding five students. Since the schools in the Weststadt, Lehndorf and Nordstadt are not equally diverse, this decision does not pose a threat to the representativeness of the data. 35 fourth graders were tested from the Nordstadt (NS; 18 monolingual, 17 multilingual), 31 from Lehndorf (LD, all monolingual), and 31 from the Weststadt (WS; 9 monolingual, 22 multilingual). All participants were born in Germany, were between 10-12 years of age at the time, and came from the immediate neighborhood of the schools involved. Overall, 58 participants were monolingual and 39 were at least bilingual. The following parent languages are represented in the sample: Turkish (17), Polish (5), Russian (4), Arabic (3), Thai (2), Italian (1), Kurdish (2), Aramaic (1), Albanian (1), Cantonese (1), English (1), Greek (1), Indonesian (1), Mandarin (1), Ukrainian (1), and an unidentified African language (1). ${ }^{9}$ Of the 39 multilingual participants, five were trilingual (students with African, Chinese, Kurdish, and Ukrainian background, as well as an Indonesian-Thai student). All speakers of Eastern European languages came from the WS, the Turkish students came from both the WS and the NS. Monolingual students provided basic background data (age, gender, nationality, place of birth, number of years living in the district, household size), but all multilinguals completed an extensive language questionnaire.

The goal of the background questionnaire was to quantify the potential influence of multilingual students' language environments. Each interview lasted between 20 and 45 minutes, and was conducted by my assistant or myself with two to

9. It was not possible to further differentiate these languages into dialects or other varieties. Having grown up in Germany, students have difficulties categorizing their parents' language in terms of regional or social dialects. 
three students at a time. The questionnaire elicited all languages spoken at home, the mixing of languages, the age of acquisition, place of acquisition, the number of years of speaking specific languages, as well as the amount of time spent in the parents' country of birth and the language use there. Students also completed a subjective family language assessment with regard to the quality and frequency of German and any other language(s) in the family. The frequency measure consisted of five values (from $1=$ "hardly ever" to 5 = "almost always"), allowing children to indicate the perceived frequency with which different interlocutors directed different languages at them in their environment. Students provided a more nuanced subjective assessment of their language environment by naming the most important interlocutors after school, specifying the language use with them, and listing the usual conversation topics. Table (4) below contains the results of the frequency assessment with these primary interlocutors. The top row indicates the language for which participants assigned a frequency value between 1 and 5 . The columns are split into the Weststadt and the Nordstadt, respectively. Lehndorf is not included because the data there only included monolinguals. The rows contain the average values for the German and parent language usage that participants assigned to primary interlocutors. The standard deviation next to the average values gives a feeling for the distribution of values. The average rating for primary interlocutors is presented below each group.

Table 4. Students' frequency rating of (unidirectional) use of German and the parent language

\begin{tabular}{lllll}
\hline Question: & $\begin{array}{l}\text { How often does/do your... speak } \\
\text { German to you? } \\
(1=\text { hardly ever, } 5=\text { almost always })\end{array}$ & $\begin{array}{l}\text { How often does/do your ... speak } \\
\text { the parent language to you? } \\
(1=\text { hardly ever, 5 = almost always) }\end{array}$ \\
\hline & $\begin{array}{l}\text { Nordstadt } \\
\text { Weststadt }\end{array}$ & $\begin{array}{l}\text { Nordstadt } \\
\text { primary interloc- }\end{array}$ & $\begin{array}{l}\text { Weststadt } \\
\text { utor I }\end{array}$ \\
$\begin{array}{l}\text { primary interloc- } \\
\text { utor II }\end{array}$ & 3.93 (s.d. 1.42) & 3.55 (s.d. 1.36) & 3.06 (s.d. 1.34) & 3.05 (s.d. 1.46) \\
$\begin{array}{l}\text { primary interloc- } \\
\text { utor III }\end{array}$ & 4.15 (s.d. 1.20) & 2.73 (s.d. 1.58) & 2.1 (s.d. 1.31) \\
$\begin{array}{l}\text { Primary com- } \\
\text { munication: }\end{array}$ & 3.56 (s.d. 1.47) & 3.71 (s.d. 1.19) & 3.8 (s.d. 1.48) & 2.94 (s.d. 1.41) \\
\hline
\end{tabular}

Friends play a limited role as primary interlocutors after school. Rather, mothers (44\%), older siblings (18\%), fathers (15\%), and younger siblings (15\%) are perceived as the most important interlocutors. The second most important interlocutors in the eyes of students are mothers (23\%), friends (22\%), older siblings (22\%), 
younger siblings (13\%), fathers (10\%) and extended family members (5\%). Two students indicated no second most important interlocutor (5\%). Overall, the data on primary interlocutors is largely based on family communication.

The backbone of data provided by the language questionnaire served the analysis of factors that are potentially predictive of students' free-sorting behavior. Five independent variables were chosen for a later factor analysis:

1. district: given the social differences between the districts, district values served as predictors reflecting the impact of the socio-economic environment of students.

2. primary language environment: the perceived primary language in students' environment could play a crucial role if language contact was responsible for certain verb clusters. Based on the primary interlocutor ratings students gave me for German and their parent language, German or the parent language was dominant or the languages were equally relevant.

3. language dominance: not knowing enough German could perhaps influence the performance in the free-sorting task. Therefore I quantified students' assessment of their language dominance based on grades they gave themselves during the interview. Again three categories resulted from this: either German or the parent language was dominant, or the two were equal. For monolinguals in the three districts, German is by default the dominant language both in their language environment and in their self-assessment.

4. parents born abroad: Both, one or no parent could be born abroad. This general categorization was created to gauge the influence of migration more generally (not only limited to language).

5. being a Turkish speaker: this is a fundamental category for testing a relationship between new lexical structures and being a Turkish speaker. Goschler et al. (2013) argued that language contact with Turkish is responsible for the patterns they found in their analysis of motion verbs in the Kiezdeutsch Corpus. Similar patterns could emerge in the free-sorting data.

These five factors were used in binomial logistic regression modelling in order to examine an intriguing co-occurrence of kommen ('to come') and schleichen ('to sneak') in the free-sorting results of certain students. The next section gives an overview of all the verbs involved in the free-sorting task.

\subsection{The List of motion verbs}

Table (5) below lists the 52 self-motion verbs and three pseudo-verbs used in the free-sorting test. To keep the free-sorting task manageable, only 38 self-motion verbs in the list were descriptive verbs, although Snell-Hornby (1983) identifies 
over 60 such verbs. To make the task more approachable for children, words that are not strictly descriptive, but frequent in relation to athletics and school sports were also added (e.g. sprinten ('to sprint'), spurten ('to spurt')). The generic verbs kommen ('to come') and gehen ('to go, walk') were relevant in Goschler et al's (2013) research and are also of interest to the broader question of Turkish-German language contact. The verb kommen ('to come') has an inherently directional meaning

Table 5. List of 52 verbs and 3 pseudo-verbs used for free-sorting

\begin{tabular}{|c|c|c|c|}
\hline German verb & Translation & German verb & Translation \\
\hline bummeln & 'to saunter' & schlendern & 'to saunter' \\
\hline eilen & 'to hurry' & schlurfen & 'to shuffle' \\
\hline flanieren & 'to stroll' & schreiten & 'to stride' \\
\hline flitzen & 'to whisk' & spazieren & 'to stroll' \\
\hline gehen & 'to walk, go' & springen & 'to jump' \\
\hline hasten & 'to hasten' & sprinten & 'to sprint' \\
\hline hechten & 'to jump' (like a pike) & spurten & 'to spurt' \\
\hline hinken & 'to limp' & stampfen & 'to stomp' \\
\hline hoppeln & 'to scamper' & stapfen & 'to trudge, tramp' \\
\hline hopsen & 'to skip' & steigen & 'to mount, rise' \\
\hline hüpfen & 'to hop' & stiefeln & 'to march' \\
\hline humpeln & 'to hobble' & stolzieren & 'to strut' \\
\hline huschen & 'to whisk' & tappen & 'to toddle' \\
\hline joggen & 'to jog' & taumeln & 'to totter' \\
\hline klettern & 'to climb' & tippeln & 'to pad' \\
\hline kommen & 'to come' & torkeln & 'to stagger' \\
\hline krabbeln & 'to crawl' & traben & 'to trot' \\
\hline kraxeln & 'to scramble' & trampeln & 'to trample, stomp' \\
\hline kriechen & 'to creep’ & trotten & 'to tread heavily' \\
\hline latschen & 'to shamble' & wandern & 'to hike' \\
\hline laufen & 'to go, walk, run' & wanken & 'to reel' \\
\hline marschieren & 'to march' & watscheln & 'to waddle' \\
\hline purzeln & 'to somersault, tumble' & wetzen & 'to speed, race' \\
\hline rasen & 'to race' & & \\
\hline rennen & 'to run' & & \\
\hline robben & 'to crawl' (like a seal) & Pseudo-verbs: & \\
\hline rollen & 'to roll' & schlopern & \\
\hline sausen & 'to dash' & somen & \\
\hline schleichen & 'to sneak' & workeln & \\
\hline
\end{tabular}


in German, while gehen ('to come') can be used both directionally (in the sense of ('to leave')) and neutrally to describe an unmarked pedestrian motion type.

\subsection{Sorting procedure \& analysis}

Participants received instructions as a group. They learned that their goal was (a) to sort verbs into groups that "fit" together, and (b) to sort out invented or unknown verbs from the set. If a student did not understand the instructions, they were repeated. The instructions were illustrated with help of the concrete example of the German verbs lachen ('to laugh'), heulen ('to weep'), grinsen ('to grin'), weinen ('to cry'), lächeln ('to smiles'), and an invented verb bammern which has no real meaning but could be a German verb due to its phonotactic structure. ${ }^{10}$ All verbs for the sorting task were printed on white business cards and presented in a sentence frame, e.g. Sie rennt. ('She is running'). Working on their own, students proceeded to sort their cards on large school tables. Enough space was provided to arrange clusters without interfering or interacting with others. Copying and cooperation were prohibited. All students were observed by my assistant, the German teacher or myself during the task. A colored sticker indicated where students had to place the verbs they perceived as non-existing. If students felt that a verb did not fit in any group (and raised the concern), they were encouraged to place it on the table alone. Each student had 30 minutes to complete the task but none took longer than 20 minutes.

Students used different strategies: Some spread the cards out on the table, sorting out perceived pseudo-verbs first and organizing the other cards afterwards. Others sorted the cards by working from a stack, subsequently creating new stacks. The method students used for sorting did not enter my analysis. We only took pictures of the final result on each table. Figure 2 contains an example of such a free-sorting result.

Table 6. Example co-variation matrix

\begin{tabular}{lccccc}
\hline & marschieren & schleichen & schreiten & traben & trotten \\
\hline marschieren & 0 & 0 & 1 & 0 & 0 \\
schleichen & 1 & 0 & 0 & 0 & 0 \\
schreiten & 0 & 0 & 0 & 0 & 0 \\
traben & 0 & 0 & 0 & 1 & 1 \\
trotten & & & & & \\
\hline
\end{tabular}

10. 'Pseudo-verbs' were included in the task to control for the overall lexical scope of speakers. The present article deals exclusively with lexical field structure within the group of known verbs. For a discussion of lexical scope, see Huenlich (2016). 
Through binary coding, all pictures of students' desks were coded as co-variation matrices, with co-occurring verbs marked, as in Table (6) above. The "1" in certain table cells indicates that marschieren ('to march') and schreiten ('to stride') as well as traben ('to trod') and trotten ('to trudge') co-occur in Figure (3), below. Schleichen ('to sneak') stands alone in Figure (3) and remains unmarked.

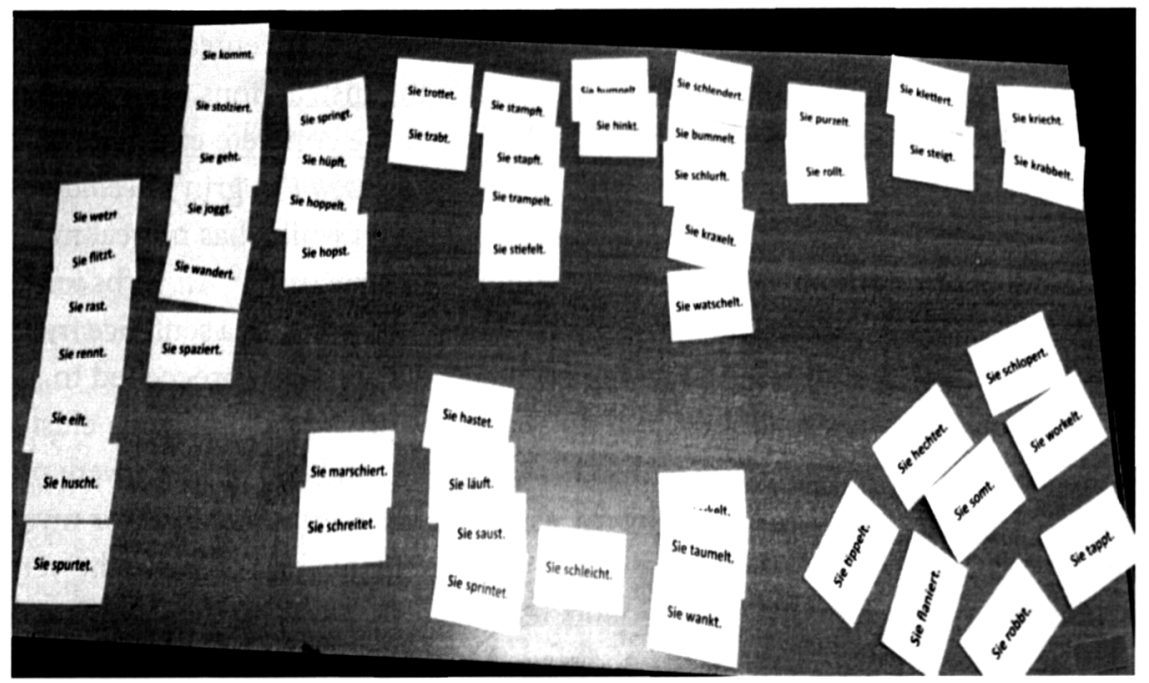

Figure 3. A student's free-sorting result

In the analysis, all results from a sample (by school, or by language background) were added up and divided by the number in the sample. The normalized matrices were then loaded into $\mathrm{R}$ as data frames and subjected to a cluster analysis which is a useful tool in locating trends in numerical tables (Baayen 2008: 138f.). Because the goal was to pinpoint relationships of perceived similarity, the method of hierarchical cluster analysis (HAC) offered itself. HAC results are usually represented in hierarchical dendrograms. Distances in these dendrograms represent a measure of similarity between two items (or groups of items). General patterns in the sorting outcomes of students can be identified and compared this way, before certain clusters or pairs of verbs can be examined more closely with help of linear regression analysis.

\section{Results}

\subsection{Dendrograms}

Cluster analysis was performed five times: in a first step, the data were analyzed by district. In a second step, the two working class districts were separated by multilingual vs. monolingual speakers across districts. The resulting dendrograms 
in Figures (4), (5) and (6) reveal general commonalities and some striking differences across districts that can eventually be explained by exceptional sorting decisions among multilinguals, as presented in Figure (8).

Height

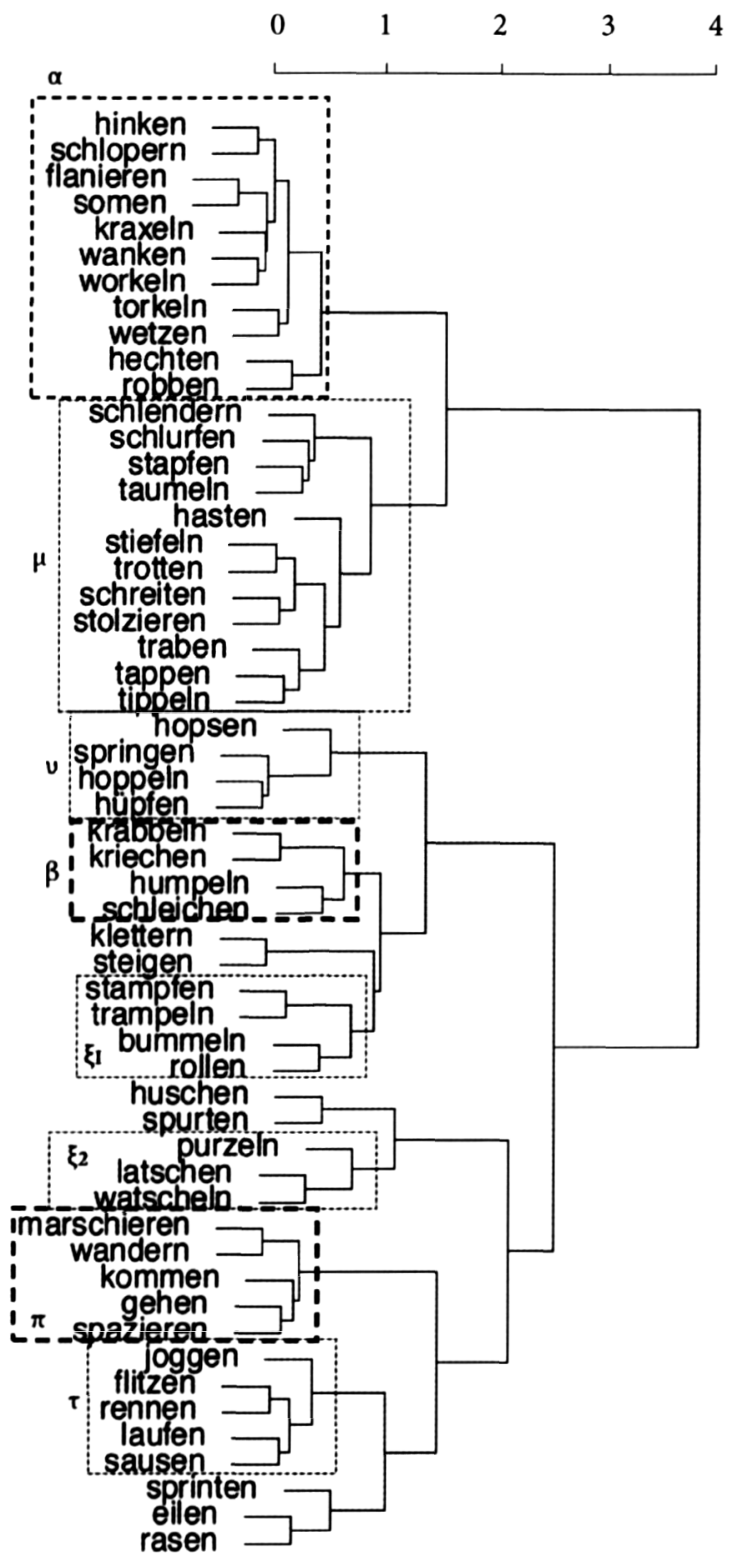

Key:

a verbs perceived as non-existent

$\mu \quad$ various 'descriptive' motion verbs

$v \quad$ jumping motion

$\beta \quad$ slow/impeded motion

$\xi_{1} \quad$ unexpected pattern : forceful/noisy motion, slow motion, ground motion

$\xi_{2} \quad$ unexpected pattern : ground motion, slow motion, other descriptive motion verb

$\pi \quad$ neutral pedestrian motion

$\tau \quad$ fast pedestrian motion

Figure 4. Dendrogram Weststadt 
Height

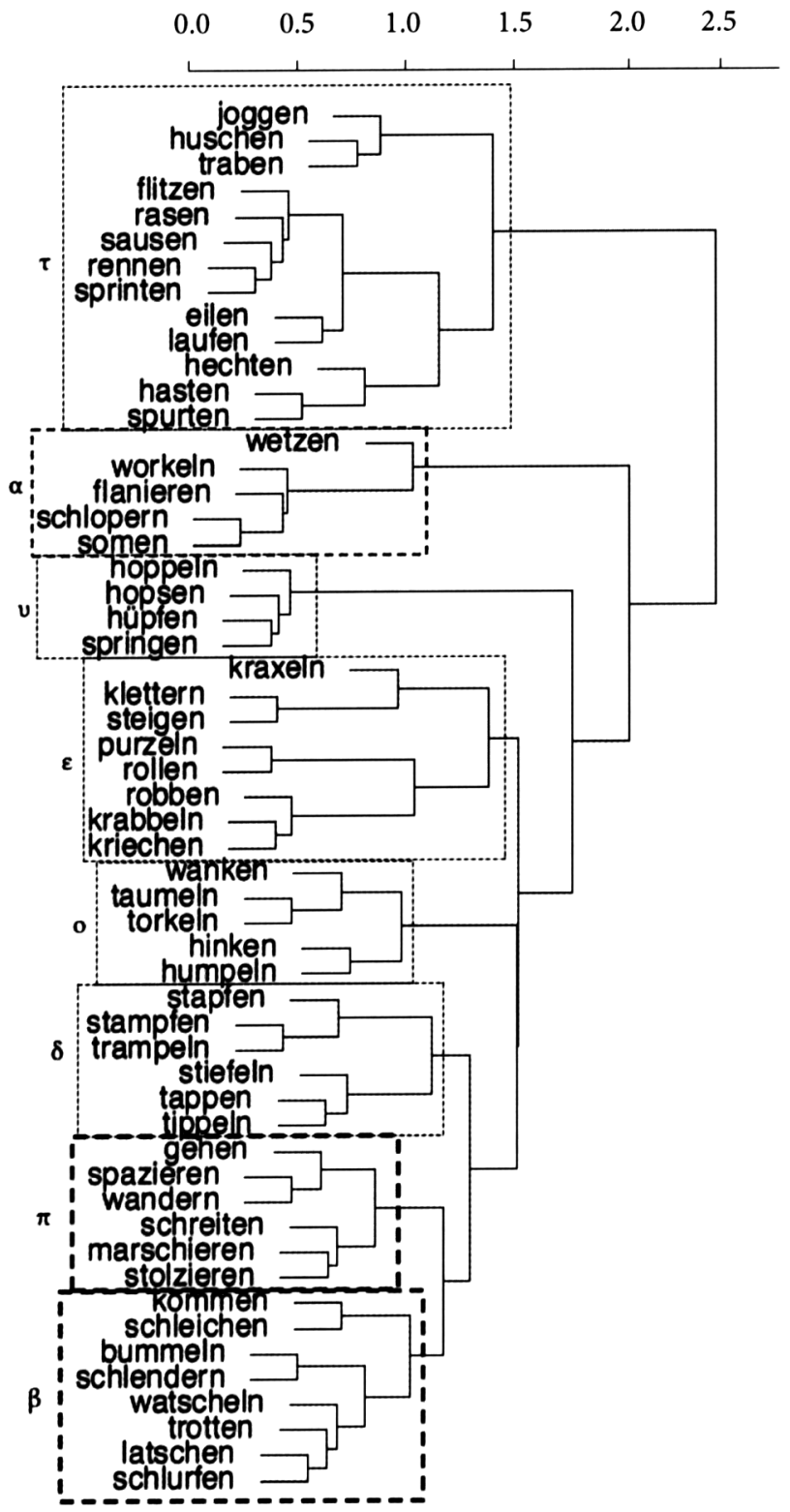

Key:

$\tau \quad$ fast pedestrian motion

a verbs perceived as non-existent

$v$ jumping motion

$\varepsilon$ ground motion

o uncontrolled motion

$\delta$ forceful motion

$\pi$ neutral pedestrian motion

$\beta$ slow/impeded motion

Figure 5. Dendrogram Lehndorf 
Height

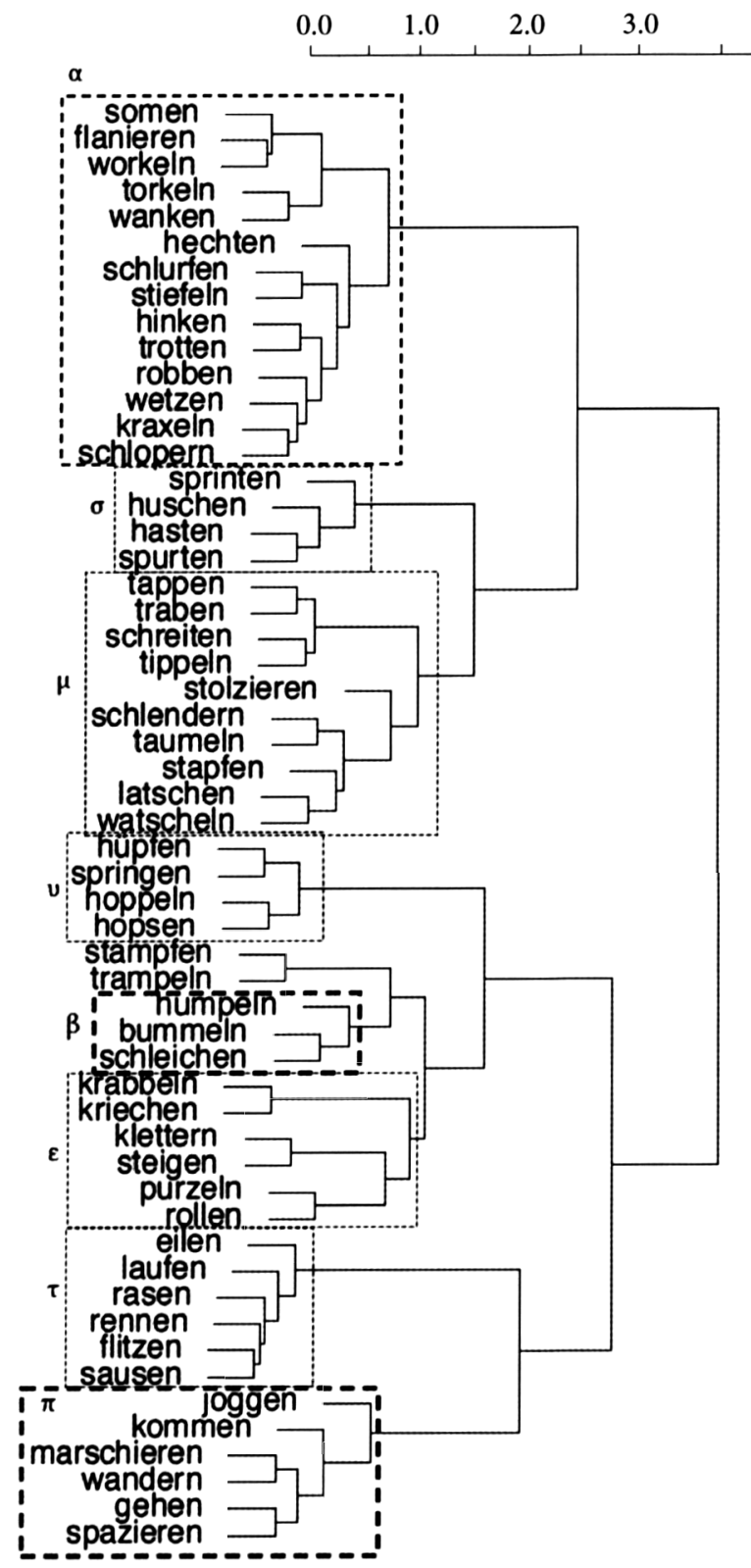

Key:

a verbs per-

ceived as

non-existent

$\sigma \quad$ fast pedestrian motion (less frequent)

$\mu \quad$ various 'descriptive' motion verbs

$v$ jumping motion

$\beta \quad$ slow/impeded motion

$\varepsilon \quad$ ground motion

$\tau$ fast pedestrian motion

$\pi \quad$ neutral pedestrian motion

Figure 6. Dendrogram Nordstadt 
Height

$$
\begin{array}{lllllll}
0.0 & 0.5 & 1.0 & 1.5 & 2.0 & 2.5 & 3.0
\end{array}
$$

$\alpha$

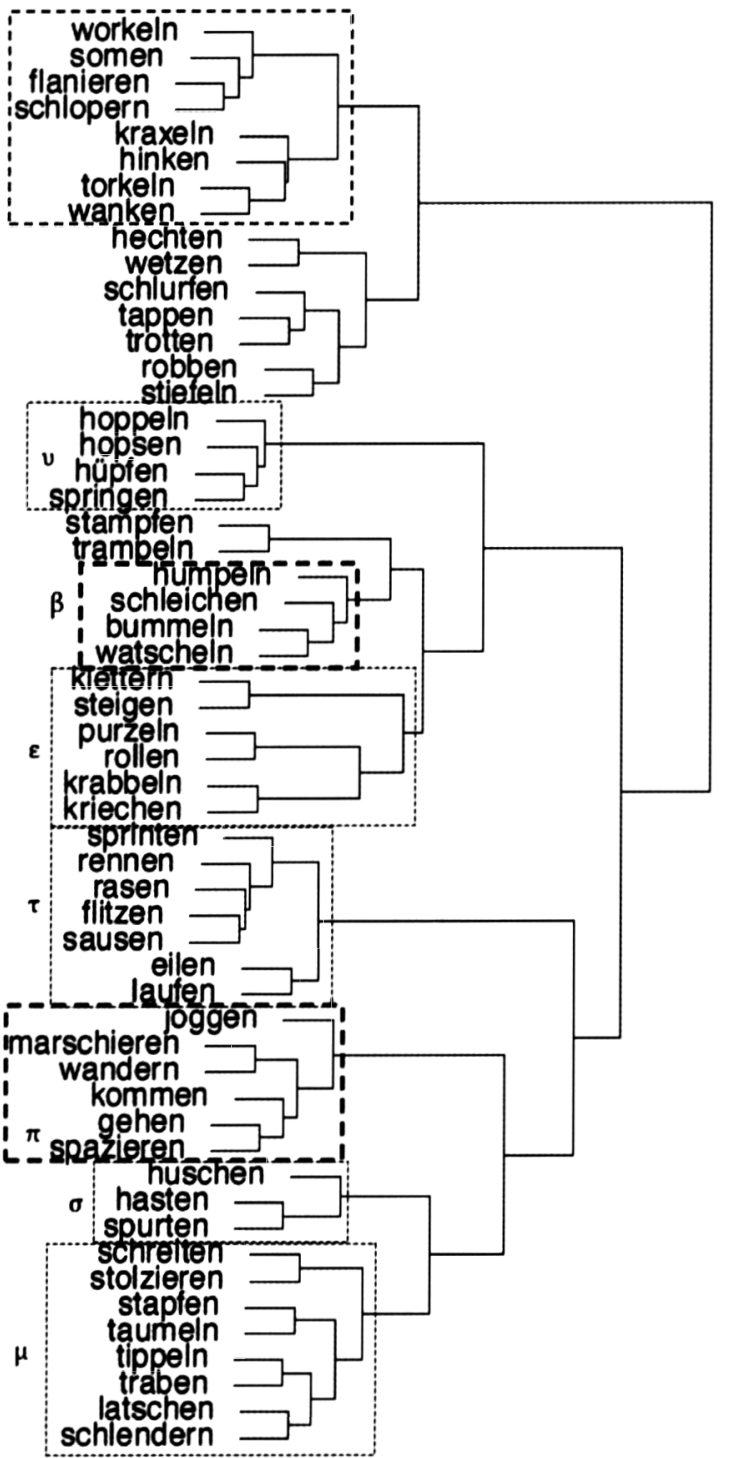

Key:

a verbs perceived as non-existent

$v$ jumping motion

$\beta$ slow/impeded motion

$\varepsilon \quad$ ground motion

$\tau$ fast pedestrian motion

$\pi \quad$ neutral pedestrian motion

$\sigma \quad$ fast pedestrian motion (less frequent)

$\mu \quad$ various 'descriptive' motion verbs

Figure 7. Dendrogram Monolinguals (WS and NS) 
Height

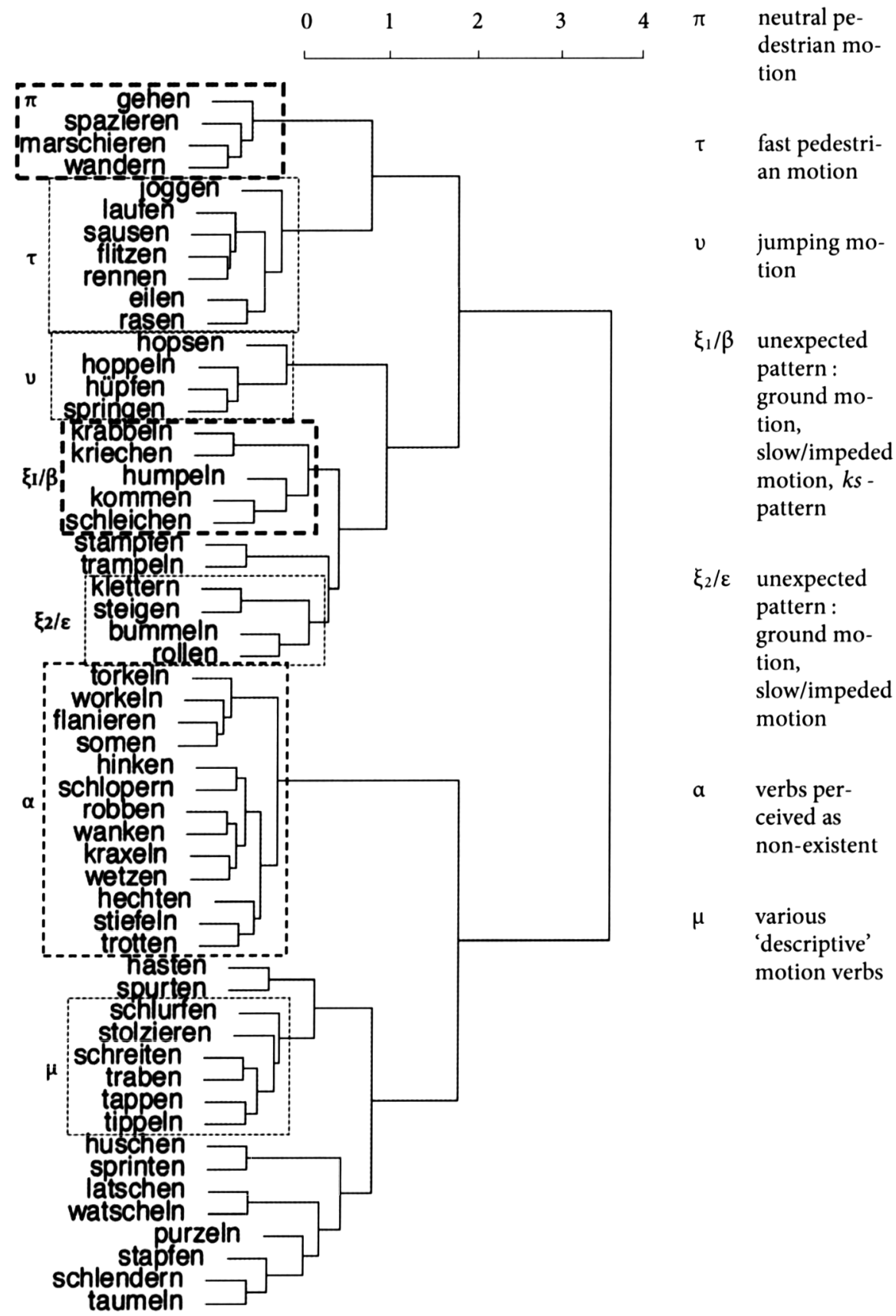

Figure 8. Dendrogram Multilinguals (WS and NS) 
All districts and speaker groups identify a neutral or leisurely group of motion verbs around gehen ('to go, walk') ( $\pi$ ), a group of fast verbs surrounding the verb rennen ('to run') $(\tau)$, and a group of verbs with the general meaning ('to jump') ( $v$ ). There also is a group of slow motion verbs $(\beta)$ in every sample.

Major differences between districts exist with regard to the size of clusters: $(\tau)$ and $(\beta)$ are very detailed large groups in Lehndorf (Figure 5), and are much narrower in the Weststadt (Figure 4) and the Nordstadt (Figure 6). The perceived pseudo-verb cluster $(\alpha)$ which contains the three pseudo-verbs somen, schlopern, workeln along with all verbs that students could assign no meaning to are substantially larger in the Weststadt and Nordstadt. A highly variable cluster $(\mu)$ that contains descriptive verbs of different types occurs in the Weststadt and Nordstadt but not in Lehndorf. The Lehndorf students create two clusters of descriptive verbs from $(\mu)$ : a cluster $(0)$ which describes uncontrolled motion types often connected to drunkenness or injury like torkeln ('to stagger') and humpeln ('to hobble'), and a cluster $(\delta)$ which contains noisy and forceful ways of walking such as stampfen ('to stomp') and stiefeln ('to march') (literally ('to boot')). A cluster that the Nordstadt and Lehndorf share but that does not occur in the Weststadt is $(\varepsilon)$. It denotes ways of moving that differ in the agents trajectory of motion and body positioning, such as klettern ('to climb'), krabbeln ('to crawl'), and rollen ('to roll'). All of these verbs describe motion events that take place close to the ground and involve quadrupedal motion. In the Weststadt, where $(\varepsilon)$ does not occur, the verbs krabbeln and kriechen which both can mean ('to crawl') are part of the slow cluster $(\beta)$ which also includes schleichen ('to sneak') and humpeln ('to hobble'). Another peculiarity of the Weststadt data is that there are several pairings of verbs that apparently have very little in common - at least in the eyes of a speaker of Standard German: rollen ('to roll') and bummeln ('to saunter') co-occur in cluster $\left(\xi_{\mathrm{I}}\right)$, for instance. Such idiosyncrasies suggested to me that the data from the Weststadt and Nordstadt should also be separated by the criterion of multilingualism. Figures (7) and (8) contain the resulting two dendrograms for all monolingual and all multilingual speakers in the two districts. A peculiar finding emerges in that kommen ('to come') occurs together with schleichen ('to sneak') for Lehndorf students and for the multilingual students of the Weststadt and Nordstadt. Being the only verb in the data set with an inherently directional sense, the attachment of kommen ('to come') to schleichen ('to sneak') in a middle class environment and in the multilingual environment is initially puzzling. Regression analysis highlights the best predictor behind this outcome, however, thereby clarifying whether language contact can actually be considered to influence this cluster - which seems unlikely at first glance since all participants in Lehndorf are monolinguals. 


\subsection{Logistic regression analysis}

While there seems to be a relationship between kommen ('to come') and schleichen ('to sneak') for the Lehndorf monolinguals and for the multilingual students in other parts of Braunschweig, it is also the case that kommen and schleichen appear immediately adjacent to the neutral cluster $(\pi)$ in Figure (5) but not in Figure (8). This means that there is an overall closer relationship between $(\pi)$ and $(\beta)$ for the students in Lehndorf than for those in Weststadt and Nordstadt. Indeed, when checking the pictures of each desk, it appears that the Lehndorf students often grouped kommen ('to come') and schleichen ('to sneak') with the neutral verbs in this sample. Multilinguals appear to associate the verb kommen ('to come') with a more active group of descriptive verbs in $\left(\beta / \xi_{\mathrm{I}}\right)$.

A way to uncover the predicting factors that determine the association of kommen with schleichen would be to treat potential co-occurrences as a binomial dependent variable, and to use the background data of students in a regression analysis to discover a possible relationship between co-occurrences and certain background factors. If a student's district best explains the sorting result, for instance, Lehndorf students would most frequently associate kommen with schleichen. If the language environment explains the association more conclusively, other predictors may prevail. Interactions between different factors are also possible.

As mentioned in Section 3.2, the predictors 'district,' 'dominant language environment,' 'subjective self-assessment of language dominance,' 'parents born abroad (one, both, none), and 'speaking Turkish' were tested. Of these predictors, being a speaker of Turkish offers the single best explanation for the association of kommen with schleichen $\left(\mathrm{p}=0.000^{\star * *}\right)$. No other predictors or interactions with other predictors offer a better explanation. A summary of the binomial logistic regression model is given in Table 7, below. Turkish speakers group together kommen and schleichen significantly more often than others in the overall sample. This can help explain at least one of the observable differences in the sorting data.

The clustering results of this section showed that there are differences in the way speakers from various districts and language backgrounds perceive the field of German motion verbs, containing lexical units (LUs) from the Self_Motion and Arriving frames. The frequency with which Turkish-speaking bilingual students clustered together the verbs schleichen ('to sneak') and kommen ('to come') confirms that language contact between German and Turkish is a possible and likely reason for the differences between the fields. The two verbs are frame-evoking Lexical Units in Standard German for the Self_Motion and Arriving frames, respectively. A re-ordering of frame-relations might be underway due to contact with Turkish: Bilinguals may be associating Lexical Units that evoke the Self Motion frame with the Arriving frame due to the inherent directional property 
Table 7. Summary of the best binomial logistic regression model.

Call: $\operatorname{glm}$ (formula $=$ ks.cluster $\sim$ Turkish, family = "binomial", data = group 1 )

Deviance Residuals:

$\begin{array}{lllll}\text { Min } & \text { QQ } & \text { Median } & \text { 3Q } & \text { Max } \\ -1.2858 & -0.5134 & -0.5134 & -0.5134 & 2.0454\end{array}$

Coefficients:

\begin{tabular}{|c|c|c|c|c|}
\hline & Estimate & Std. Error & $z$ value & $\operatorname{Pr}(>|z|)$ \\
\hline (Intercept) & -1.9601 & 0.3378 & -5.803 & $6.51 \mathrm{e}-09^{\star * *}$ \\
\hline Turkish(yes) & 2.2114 & 0.6067 & 3.645 & $0.000267^{\star * *}$ \\
\hline $\begin{array}{l}\text { Signif. codes: } \\
\text { (Dispersion } p \\
\text { Null deviance } \\
\text { Residual devi } \\
\text { AIC: } 86.479\end{array}$ & $\begin{array}{l}\text { neter for bi } \\
\text { meter } 959 \text { on } 96 \\
82.479 \text { or } \\
\text { ber of Fish }\end{array}$ & 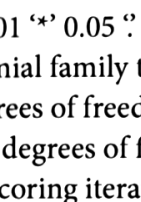 & $\begin{array}{l}\text { "' } 1 \\
\text { n to be } 1 \text { ) } \\
\text { dom } \\
\text { Is: } 4\end{array}$ & \\
\hline
\end{tabular}

of Turkish motion verbs. Alternatively, the two frames may be merging into a new frame in a contact variety of German.

But which frame elements would be part of such a new frame? While it is not possible to replicate the density of a corpus-based analysis in the framework of my study, the next section presents a video-guided feedback session I conducted with participants which revealed a constructional change that potentially induces the observed phenomenon and that would have immediate consequences for a possible merged frame.

\section{Follow-up measure: Participant Feedback}

In 2013, the year following the free-sorting test, I organized a video-guided feedback session with several students that had grouped together the verbs kommen ('to come') and schleichen ('to sneak') (henceforth, $k s$-cluster). Instead of discussing the test, I presented video stimuli to the students this time and asked them to provide suitable descriptions of the videos. Six of fifteen students who had previously produced the $k s$-cluster were available for the follow-up interview (WS, four students; NS, two students). I also included students who had not produced the $k s$-cluster in the previous year. Overall, fourteen participants offered feedback. 


\subsection{Video stimuli and Procedure}

To produce the stimuli, I filmed an actor silently performing different motion types, namely jumping, doing a summersault, crawling, stomping, jumping across two benches, climbing over a fence, walking normally, walking lazily and walking quietly. Five of these motion types were recorded twice from different directions. Each video was 3-5 seconds long. Two videos of deliberate, quiet and slow motion typically expressed with the verb schleichen ('to sneak') in Standard German were used as target stimuli (although I was also interested in other clusters at the time). I asked the actor to look back deliberately in one of the sneaking-videos, in order to emphasize that he was 'sneaking away'. My reasoning was that a trajectory away from a source location might trigger a different association than with kommen ('to come, arrive'). Images taken from the sneaking videos are given below in Figures 9a and 9b.

All stimuli were presented in random order to the students. Due to time restrictions, they participated in pairs. To get an impression of possible contrasting perceptions, I paired target students who had produced a $k s$-cluster a year prior to the interview with observing students who had not produced the $k s$-cluster. The target student of each pair stood in front of a laptop screen while the observing student video-recorded the target student. ${ }^{11}$

In addition to the video clips, fifteen verb cards were placed on the table next to the laptop. These cards gave students the chance to reconnect to the free-sorting experiment in the past year. I first asked each of the target students to describe in their own words what the screen showed. After they commented on the video clip, I directed the attention to the cards on the table and had the student choose one or more cards that best described the video. Some students associated many verbs with the motion event shown, while others only chose a single verb. I also asked students to explain their choices. After the target students commented on all fourteen videos, laid out the verbs they found fitting and commented on the target words, I asked the observing student behind the camera whether they would have made the same choices as the target student. Observing students sometimes offered interesting additions or made clear where they would not have made the same choice.

\subsection{Student feedback}

Given a year had passed between the free-sorting test and the second meeting and video task with the students, I was skeptical that students would reproduce

11. By employing the observing students as camerapersons the task gained their interest and I was free to focus on the target student and assist where necessary. 


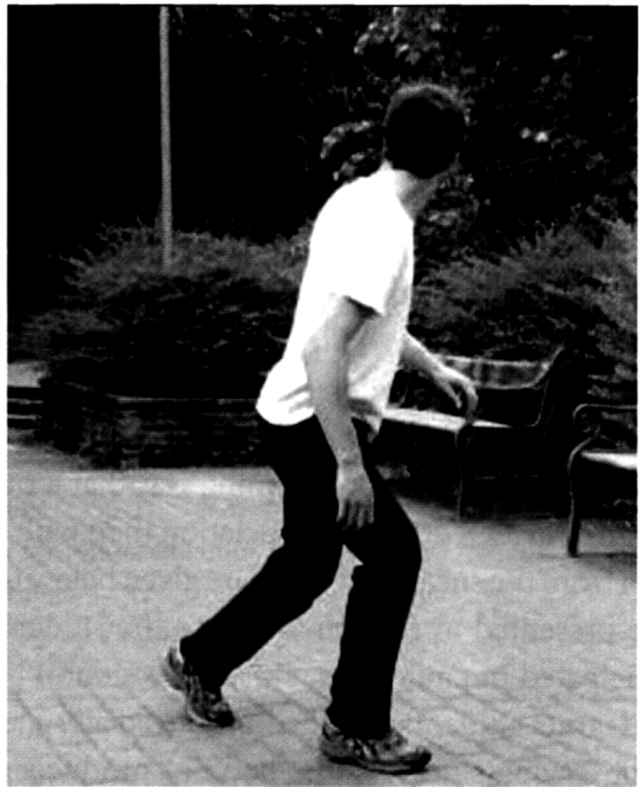

Figure 9a. schleichen-video 1, looking back

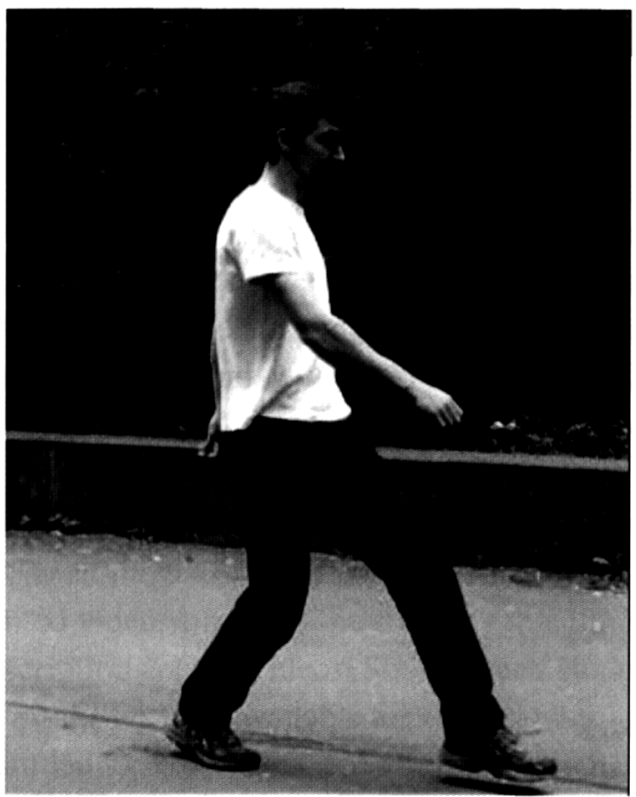

Figure 9b. schleichen-video 2, looking ahead

the cluster of kommen ('to come') and schleichen ('to sneak') from the sorting data. However, the patterns did resurface when I presented participants with the videos. In four instances, the target students chose Er schleicht ('he is sneaking') 
and Er kommt ('he is coming') as the best descriptions for Pictures 9a and 9b, respectively. The first student of Turkish origin in the Nordstadt described the two ('sneaking') clips as follows.

For (9a):

(6) Der Mann schleicht und schleicht sich und guckt nach hinten.

$3 \mathrm{sm}$ man sneak.3s and sneak.3s REFL and look DIR back

'The man is sneaking and sneaking (reflexive) and looking back

For (9b):

(7) Er schleicht sich wieder!

3sm sneak.3s REFL again

Standard German: Er schleicht sich wieder an!

'He is creeping up [on someone/somebody] again!'

Interestingly, (6) and (7) contain a peculiar construction syntactically speaking: the reflexive construction sich schleichen ('to sneak oneself') does not exist in Standard German without a directional complement. A similar construction only exists in Southern German dialects, where it means that someone ('makes off'). But it is unlikely that students are familiar with this meaning due to the geographical distance to Southern German dialects. Rather, it seems that the student is actually omitting words or parts of the sentence - a phenomenon well documented in studies of ethnic varieties of German (cf. Dirim \& Auer 2004, Keim 2007). As mentioned in Section 2.2, descriptive verbs in Standard German are always combined with directional particles when a directional motion event is described. The particles an ('at/toward'), ein ('in/into'), and weg ('away'), when added to schleichen, for instance, result in the composite verbs anschleichen ('sneak up, creep up'), einschleichen ('sneak in') and wegschleichen ('sneak away'). In a Standard German main clause, the stem of these verbs would stand in the second position and the particles would appear in the last position of the sentence. In sentence (8), below, the main clauses with the verb hingehen ('to go to') and anschleichen ('sneak up') exemplify this: the verbs separate and flip their order to geht...hin and schleicht ... an. In contrast, hingehen remains connected because the verb is in a subordinate clause.

Some composite forms actually require a reflexive pronoun in German, such as sich anschleichen ('sneak up or') sich einschleichen ('sneak in'). An omission of the directional particle would then yield sich schleichen which is not Standard German but which appears to be what the student in (6) and (7) is doing.

Example 8 confirms this: another Turkish speaker intensely focused on the card reading Er kommt after selecting Er schleicht the best fit to the second video. I asked what the student was looking at. She gave me the following explanation 
of why kommen was actually part of her perceptual experience when seeing this video. In her explanation, she uses a directional composition of $h$ in ('towards') and gehen ('to go'):

(8) Wenn er schleicht, dann geht er irgendwo hin. er schleicht sich an If he sneaks then goes he somewhere DIR he sneaks REFL DIR weil er leise sein möchte und irgendwo hingehen möchte, beispiel so because he quiet be want.3s and somewhere DIR-go want.3s example FOC erschrecken. Dann schleicht man sich oder irgendwas scare then sneak 3s REFL or something Last sentence in Standard German: Dann schleicht man sich an oder irgendwas

'If he sneaks, then he is going somewhere. He creeping up on [someone] because he wants to be quiet and wants to go somewhere - for example to scare [someone]. Then you sneak yourself (reflexive marker) or something.'

From these comments, there appears to be an inherently intentional and directional understanding of the action of sneaking. Also, sich schleichen occurs once with and once without a particle in (8). It is therefore very likely, that there is variation with respect to the omission of the directional particle. Directionality is grammatically still evident from the remaining reflexive pronoun sich (which only occurs with schleichen in a directional sense) so it is actually a redundant feature here.

The possible constructional change documented in (6), (7) and (8) can be summarized as follows: schleichen ('to sneak') is a non-directional descriptive verb in Standard German that can combine with different directional prefixes. It turns into a reflexive verb when combined with some of these particles in Standard German. Due to the frequent omission of directional separable prefixes in certain German vernaculars, however, it appears that an inherently directional sense of the sneaking-event is now associated with the verb stem and that, in addition, the reflexive marker sich fulfils the function of the directional marker. Similar to Turkish motion event descriptions, there is no directional marker in the form of a satellite particle in the constructions in (6), (7) and (8). Unlike Turkish, however, the new construction encodes manner and direction. Although the lexical material has been reduced it maintained the semantic properties of a descriptive verb. The question remains whether this phenomenon of inherent directionality also holds for other descriptive verbs or not. Omissions of separable prefixes were not evident for the other verbs in the follow-up measure, as the present test focused on the observations made for the verb schleichen. It is thus necessary to test other verbs in a different setting. 


\section{The suggested frame change}

Given the constructional change described in the previous section, we may now formalize the frame that could be equally evoked by kommen ('to come') and schleichen ('to sneak'). Due to the limited representativeness of my data, I will focus on the core frame elements (FEs). An important observation when comparing the FEs of Arriving with those of Self_Motion is that both frames conceptualize MANNER as a Non-core FE. This is due to the circumstance that the verb itself often encodes MANNER in the Self_Motion frame while MANNER is generally left unencoded in the Arriving frame. This difference is bridged by the novel use of the verb schleichen but it does not materialize in the FEs of Self_Motion and Arriving. The omission of a particle in sentences (6), (7) and (8) has a direct effect on the FEs, however. First, the FE GOAL which is a Core element of Self_Motion changes in nature. The description of Arriving in FrameNet states that the GOAL is always "conceptually present and specific," but sometimes also "understood from context rather than expressed by any separate constituent." Based on the data above, certain FEs of Self_Motion are tentatively less crucial for the newly emerging frame. The same contextual cues that define the GOAL often also specify the

Table 8. A comparison of Frame Elements

\begin{tabular}{llll}
\hline $\begin{array}{l}\text { Core } \\
\text { FEs }\end{array}$ & Self_Motion & Arriving & Frame causing $k s$-pattern \\
\hline $\begin{array}{l}\text { Agent } \\
\text { Self_mover is the living } \\
\text { being which moves under } \\
\text { its own power. Normally it } \\
\text { is expressed as an external } \\
\text { argument. }\end{array}$ & $\begin{array}{l}\text { Theme is the object that } \\
\text { moves. It may be an entity } \\
\text { that moves under its own } \\
\text { power, but it need not be. }\end{array}$ & $\begin{array}{l}\text { Agent is a living being } \\
\text { which moves under its } \\
\text { own power. Normally it is } \\
\text { expressed as an external } \\
\text { argument. }\end{array}$ &
\end{tabular}

Goal Refers to where the Self__ Refers to where the Theme

Refers to where the Agent mover ends up as a result of the motion. Some particles ends up as a result of the ends up as a result of the imply the existence of a Goal motion. Although always

conceptually present motion. Although always conceptually present which is understood in the context of utterance. and specific, Goal may sometimes be understood from context, rather than expressed by any separate constituent.

Path Path is used for any description of a trajectory of motion which is neither a Source nor a Goal. and specific, Goal may sometimes be understood from context, rather than expressed by any separate constituent.

Path is a description of a trajectory of motion. It is neither a Source nor a Goal.

This includes "middle of path" expressions. 
direction of motion. The FEs AREA and SOURCE are currently not confirmed in my data. The trajectory, however, does not vanish from the surface representation: The FE PATH is obligatory for Self_Motion and the reflexive pronoun sich in sentences (6), (7) and (8) has a very similar function: because it refers to the moving agent, then by definition it is neither an expression of a GOAL or sourCE. Nevertheless it implies a trajectory of motion. What emerges from all these observations is a mixed picture with traits from both frames. A summary of the similarities and differences between the three frames is given in Table 8 .

\section{Conclusion}

The goal of this paper was to make initial observations on the way frames operate across languages in contact and how they may be influenced by changing constructions. Language contact between German and Turkish in immigrant neighborhoods of Germany served as a potential case for such changes. The sorting-test at schools in Braunschweig and the video-guided feedback session resulted in the following observations.

First, the dendrograms in Figures (4) to (8) showed that the differences in perception of motion verbs across the three districts involved are substantial. They become even more pronounced when multilingual and monolingual speakers in the working class neighborhoods are compared in their sorting choices.

Second, the dendrogram of multilinguals and of the middle class neighborhood revealed an association of the verbs schleichen ('to sneak') and kommen ('to come') which are thought to evoke the Self_Motion and Arriving frame, respectively, in Standard German. The pairing of these LUs is therefore rather surprising.

The third observation arose from an investigation of the co-occurrences of schleichen ('to sneak') and kommen ('to come') ( $k s$-cluster) by means of binomial logistic regression using five predictors from participants background questionnaires to see what the best possible explanation of the co-occurrence may be. The results showed that being a speaker of Turkish is by far the most predictive variable for this pairing $\left(\mathrm{p}=0.000^{* * *}\right)$. The German Self_Motion and Arriving frame could be restructuring or homogenizing under the influence of Turkish. Given that the $k s$-cluster also occurs in the middle class neighborhood, however, it is also possible that the pairing is due to an effect of frequency: schleichen might occur more often in contexts of arrival than other descriptive verbs. Investigating frequency effects was beyond the scope of my study, but is an important aspect to explore in future work.

An observation in favor of the interpretation that frame changes are underway came from the feedback which participants offered when they watched the video with the sneaking actor: in four cases, participants who had produced the $k s$-cluster 
earlier used both the verbs schleichen ('to sneak') and kommen ('to come') to describe the video. From the description it became clear that direction was a crucial component to all participants. However, the construction students used to describe the event was also missing the separable prefixes that usually encode direction in Standard German and its dialects. The new construction is different in that the verb stem and a reflexive marker serve to encode directional information rather than the expected particle or prepositional phrase. This finding corroborates Goschler et al.'s (2013) observation that speakers of Turkish background avoid directional particles when using manner verbs. If morphosyntactic omissions of directional particles (perhaps under the influence of the V-language background of Turkish) leave a mark on the lexicon of Turkish-German speakers, the association of schleichen ('to sneak') and kommen ('to come') seems less surprising than if it would occur in a middle class neighborhood of monolingual German-speakers. It seems, however, that there is an inherent directionality to the verb schleichen ('to sneak') that also influenced the sorting choice of German monolinguals in Lehndorf.

While the findings of this paper are not conclusive in nature, they suggest that in the process of language contact, frames are not exempt from language change. It makes sense to assume a single linguistic system in which frames initially may conflict but eventually 'reframe' the conceptual experiences of speakers. Future research must further explore the nature of frames across stages of homogenization or reduction. Establishing large bilingual FrameNet corpora across generations of bilinguals may prove useful in investigating these phenomena and may lead to claims of broader validity.

\section{References}

Baayen, R. H. (2008). Analyzing Linguistic Data: A Practical Introduction to Statistics using R. Cambridge: Cambridge University Press. https://doi.org/10.1017/CBO9780511801686

Baker, C. F., Fillmore, C. J., \& Lowe, J. B. (1998). The Berkeley FrameNet Project. In Association for Computational Linguistics (Eds.), Proceedings of the 17th International Conference on Computational Linguistics - Volume 1 (COLING '98) (pp. 86-90). Stroudsburg, PA, USA.

Boas, H. (2013). Frame Semantics and Translation. In A. Rojo, \& I. Ibarretxe-Antuñano (Eds.), Cognitive Linguistics and Translation. Advances in Some Theoretical Models and Applications (pp. 125-158). Berlin: de Gruyter. https://doi.org/10.1515/9783110302943.125

Croft, W. (2009). Connecting frames and construction: a case study of eat and feed. Constructions and Frames, 11, 7-28. https://doi.org/10.1075/cf.1.1.02cro

Dirim, İ. \& Auer, P. (2004). Türkisch sprechen nicht nur die Türken. Über Unschärfebeziehungen zwischen Sprache und Ethnie in Deutschland. Berlin: Walter De Gruyter.

Fillmore, C. J., \& Atkins, B. T. (1992). Toward a frame-based lexicon: The semantics of RISK and its neighbors. In A. Lehrer, \& E. Feder-Kittay (Eds.), Frames, fields and contrasts: New essays in semantic and lexical organization (pp. 75-102). Hillsdale, N. J.: Lawrence Erlbaum. 
Fillmore, C. J. (1968). The Case for Case. In Bach, \& Harms (Eds.), Universals in Linguistic Theory (pp. 1-88). New York: Holt, Rinehart, and Winston.

Fillmore, C. J. (1982). Frame semantics. In Linguistic Society of Korea (Eds.), Linguistics in the Morning Calm (pp. 111-137). Seoul: Hanshin Publishing Co.

Fillmore, C. J. (2008). Border conflicts: FrameNet meets construction grammar. In E. Bernal, \& J. DeCesaris (Eds.), Proceedings of EURALEX13 (pp. 49-68). Barcelona: Universitat Pompeu Fabra.

Goschler, J. et al. (2013). Beyond conflation patterns: The encoding of motion events in Kiezdeutsch. In A. Stefanowitsch, \& J. Goschler (Eds.), Trends in Cognitive Linguistics. Yearbook of the German Cognitive Linguistics Association (pp. 237-252). Berlin: Mouton de Gruyter.

Höder, S. (2012). Multilingual constructions: a diasystematic approach to common structures. In Braunmüller, K. \& Gabriel, C. (Eds.), Multilingual individuals and multilingual societies (Hamburg Studies on Multilingualism 13) (pp. 241-257). Amsterdam/Philadelphia: Benjamins.

Höder, S. (2014). Constructing diasystems. Grammatical organisation in bilingual groups. In Åfarli, T. A. \& Mæhlum, B. (Eds.), The sociolinguistics of grammar (Studies in Language Companion Series 154) (pp. 137-152). Amsterdam/Philadelphia: Benjamins.

Huenlich, D. (2015). Exploring Word Fields Using the Free-Sorting Method. In C. Brown, Q. Gu, C. Loos, J. Mielens, \& G. Neveu (Eds.), Proceedings of the 15th Texas Linguistic Society (pp. 73-90). Austin: The University of Texas at Austin.

Huenlich, D. (2016). The Roots of 'Multiethnolects': Effects of Migration on the Lexicon and Speech of German-Speaking School Children. (Unpublished Doctoral Dissertation). Austin: The University of Texas at Austin.

Keim, I. (2007). Die "türkischen Powergirls". Lebenswelt und kommunikativer Stil einer Migrantinnengruppe in Mannheim. Tübingen: Narr.

Özçalişkan, S. \& Slobin, D. I. (1999). Learning how to search for the frog: Expression of manner of motion in English, Spanish, and Turkish. In A. Greenhill, H. Littlefield, \& C. Tano (Eds.), Proceedings of the $23^{\text {rd }}$ annual Boston University conference on language development, Vol. 2 (pp. 163-174). Somerville, MA: Cascadilla Press.

Roberson, D. et al. (2005). Free-sorting of colors across cultures: Are there universal grounds for grouping? Journal of Cognition and Culture, 5(3), pp. 349-386. https://doi.org/10.1163/156853705774648536

Slobin, D. I. (1996). Thinking for Speaking. In J. Gumperz \& S. Levinson (Eds.), Rethinking Linguistic Relativity (pp. 271-323). Cambridge: Cambridge University Press.

Slobin, D. I. (2000). Verbalized events: A dynamic approach to linguistic relativity and determinism. In S. Niemeier \& R. Dirven (Eds.), Evidence for linguistic relativity (pp. 107-138). Amsterdam/Philadelphia: John Benjamins.

Snell-Hornby, M. (1983). Verb-descriptivity in German and English: A Contrastive Study in Semantic Fields. Heidelberg: Winter.

Talmy, L. (1985). Lexicalization Patterns: Semantic Structure in Lexical Forms. In T. Shopen (Ed.), Grammatical Categories and the Lexicon, Vol. 3. (pp. 57-149). Cambridge: Cambridge University Press.

Talmy, L. (2000). Toward a Cognitive Semantics 2: Typology and Process in Concept Structuring. Cambridge: MIT Press. 